\title{
Caracterização de indivíduos com câncer, residentes no meio rural, práticas no uso de agrotóxicos e níveis de acetilcolinesterase eritrocitárias
}

\author{
Characterization of individuals with cancer, residing in rural areas, practices in the use of \\ pesticides and levels of erythrocyte acetylcholinesterase \\ Caracterización de individuos con cáncer, residentes en áreas rurales, prácticas en el uso de \\ plaguicidas y niveles de acetilcolinesterasa eritrocitaria
}

Recebido: 14/04/2021 | Revisado: 25/04/2021 | Aceito: 02/05/2021 | Publicado: 16/05/2021

Sandra Emilia Drews Montagner
ORCID: https://orcid.org/0000-0002-2141-0063
E-mail: sandrinhadrews@yahoo.com.br
Christiane de Fátima Colet
Universidade Regional do Noroeste do Estado
ORCID: https://orcid.org/0000-0003-2023-5088
E-mail: christiane.colet@ @unijui.edu.br
Keli Luana Maldaner
Universidade Regional do Noroeste do Estado
ORCID: https://orcid.org/0000-0001-9319-3558
E-mail: keli.maldaner@ hotmail.com
José Antônio Gonzales da Silva
ORCID: https://orcid.org/0000-0002-9335-2421
Universidade Regional do Noroeste do Estado do Rio Grande do Sul, Brasil
E-mail: jose.gonzales@ unijui.edu.br
Ana Paula Weber Fell
Universidade Regional do Noroeste do Estado do Rio Grande do Sul, Brasil
ORCID: https://orcid.org/0000-0002-4999-7919
E-mail: ana.fell@ @ sou.unijui.edu.br
Roberto Carbonera
Universidade Regional do Noroeste do Estado do Rio Grande do Sul, Brasil
ORCID: https://orcid.org/0000-0001-8686-2047
E-mail: carbonera@ @unijui.edu.br
Eniva Miladi Fernandes Stumm
ORCID: https://orcid.org/0000-0001-6169-0453
Universidade Regional do Noroeste do Estado do Rio Grande do Sul, Brasil
Eniversidade Regional do Noroeste do Estado do Rio Grande do Sul, Brasil
E-mail: eniva@ @unijui.edu.br

\section{Resumo}

O objetivo do presente estudo foi caracterizar indivíduos do meio rural, diagnosticados com câncer, quanto às práticas no uso de agrotóxicos, sintomas físicos, emocionais, de intoxicação e níveis de acetilcolinesterase eritrocitária. Tratase de pesquisa transversal, quantitativa, descritiva, em hospital geral, com 92 pacientes oncológicos e agricultores. $\mathrm{O}$ projeto foi aprovado pelo CEP sob o número 2.626.873. Instrumento de coleta de dados com variáveis sociodemográficas, práticas no manuseio de agrotóxicos e mensuração da acetilcolinesterase eritrocitária. A análise dos dados com programa Statistical Package for Social Science, estatística descritiva e analítica. Os resultados demonstraram que a maioria do sexo masculino, idoso, baixa escolaridade. Predominam pequenas propriedades rurais, cultivo de hortifrutigranjeiros. 63\% expostos ocupacionalmente a agrotóxicos; para proteção, 56,8\% usam botas, "sempre". Orientação técnica insuficiente. Baixa frequência de intoxicação. Menor média de acetilcolinesterase eritrocitária no grupo exposto a agrotóxicos ativo, estatisticamente significativa. Evidenciou-se o predomínio de agricultura familiar, com produção de hortifrutigranjeiros e uso de equipamentos que favorecem o contato direto com agrotóxicos, inclusive uso inadequado de EPIs. Lacunas quanto ao uso seguro destes produtos, provavelmente relacionada à escolaridade, os tornam suscetíveis a agravos da exposição direta e indireta. Mensuração da acetilcolinesterase eritrocitária mostrou valores médios normais e requer exames complementares e monitoramento contínuo. Resultados remetem à ações e intervenções educacionais com vistas à prevenção de agravos e redução dos índices crescentes de câncer nesta população.

Palavras-chave: Oncologia; Agroquímicos; Equipamentos de proteção individual; Saúde do trabalhador rural; Segurança. 


\begin{abstract}
The aim of the present study was to characterize individuals from rural areas, diagnosed with cancer, regarding the practices in the use of pesticides, physical, emotional symptoms, intoxication and levels of erythrocyte acetylcholinesterase. This is a cross-sectional, quantitative, descriptive study, in a general hospital, with 92 cancer patients and farmers. The project was approved by CEP under number 2,626,873. Data collection instrument with sociodemographic variables, practices in handling pesticides and measurement of erythrocyte acetylcholinesterase. Data analysis using the Statistical Package for Social Science program, descriptive and analytical statistics. The results showed that the majority of the male, elderly, had a low level of education. Small rural properties predominate, cultivation of fruits and vegetables. $63 \%$ occupationally exposed to pesticides; for protection, $56.8 \%$ wear boots, "always". Insufficient technical guidance. Low frequency of intoxication. Lower average of erythrocyte acetylcholinesterase in the group exposed to active pesticides, statistically significant. There was a predominance of family farming, with the production of fruit and vegetables and the use of equipment that favors direct contact with pesticides, including the inappropriate use of PPE. Gaps regarding the safe use of these products, probably related to education, make them susceptible to aggravations of direct and indirect exposure. Measurement of erythrocyte acetylcholinesterase showed normal mean values and requires complementary exams and continuous monitoring. Results refer to actions and educational interventions aimed at preventing diseases and reducing the growing rates of cancer in this population.
\end{abstract}

Keywords: Oncology; Agrochemicals; Equipments for individual safety; Rural worker health; Safety.

\title{
Resumen
}

El objetivo del presente estudio fue caracterizar a individuos de áreas rurales, diagnosticados de cáncer, en cuanto a las prácticas en el uso de plaguicidas, síntomas físicos, emocionales, intoxicación y niveles de acetilcolinesterasa eritrocitaria. Se trata de un estudio transversal, cuantitativo, descriptivo, en un hospital general, con 92 pacientes oncológicos y agricultores. El proyecto fue aprobado por el CEP con el número 2.626.873. Instrumento de recolección de datos con variables sociodemográficas, prácticas en el manejo de plaguicidas y medición de acetilcolinesterasa eritrocitaria. Análisis de datos mediante el programa Statistical Package for Social Science, estadística descriptiva y analítica. Los resultados mostraron que la mayoría de los hombres, ancianos, tenían un bajo nivel de educación. Predominan las pequeñas propiedades rurales, cultivo de frutas y hortalizas. 63\% ocupacionalmente expuestos a plaguicidas; por protección, el 56,8\% usa botas, "siempre". Orientación técnica insuficiente. Baja frecuencia de intoxicaciones. Promedio más bajo de acetilcolinesterasa eritrocitaria en el grupo expuesto a plaguicidas activos, estadísticamente significativo. Predominó la agricultura familiar, con la producción de frutas y hortalizas y el uso de equipos que favorecen el contacto directo con plaguicidas, incluido el uso inadecuado de EPI. Las lagunas con respecto al uso seguro de estos productos, probablemente relacionadas con la educación, los hacen susceptibles a agravamientos de la exposición directa e indirecta. La medición de la acetilcolinesterasa eritrocitaria mostró valores medios normales y requiere exámenes complementarios y monitorización continua. Los resultados se refieren a acciones e intervenciones educativas dirigidas a prevenir enfermedades y reducir las crecientes tasas de cáncer en esta población.

Palabras clave: Oncología; Agroquímicos; Equipos para la seguridad individual; Salud del trabajador rural; Seguridad.

\section{Introdução}

A expansão e modernização da agricultura tem exposto os seres humanos à substâncias químicas diversas no seu macro ambiente, na alimentação e em seu ambiente de trabalho. A busca incessante pelo aumento da produtividade agrícola é responsável pelo incremento no uso de agrotóxicos (Carneiro et al., 2015). Dados da mesma fonte apontam que, enquanto o consumo mundial de agrotóxicos cresceu 93\% entre 2004 e 2013, o mercado brasileiro expandiu 190\% e posicionou o Brasil como maior consumidor mundial de agrotóxicos desde 2008.

A produção agrícola mecanizada é justificada pela crescente necessidade de alimentos (Jobim et al., 2010), entretanto, o aumento da produtividade no campo traz repercussões negativas no âmbito da saúde e do meio ambiente, principalmente no que tange à toxicidade (Rigotto et al., 2014). Anteriormente chamados "defensivos agrícolas", os agrotóxicos passaram a ser assim chamados a partir da Constituição Federal de 1988, baseado nas evidências da toxicidade destes compostos (Fundação Nacional de Saúde, 1998).

O Sistema Nacional de Informações Tóxico-Farmacológicas (SINITOX) aponta que, em 2012, último ano com registros de intoxicações por agrotóxicos no site, $24,6 \%$ dos casos de intoxicação por agrotóxicos de uso agrícola ocorreram em ambiente de trabalho e 24,3\% por acidente individual (Sistema Nacional de Informações Tóxico-Farmacológicas, 2015). O 
uso inadequado, toxicidade e falta de equipamentos de proteção individual são possíveis causas (Mello \& Silva, 2013). O IBGE estima 32 milhões de pessoas na zona rural brasileira, 12 milhões economicamente ativas (Jobim et al., 2010), expostas à contaminação respiratória ou dérmica, nas diferentes etapas de manuseio dos agrotóxicos ou próximas à áreas de pulverização. Há indícios de contaminação alimentar. Exposições diretas ou indiretas resultam em intoxicações agudas, de efeitos imediatos na saúde do indivíduo e de fácil diagnóstico, ou crônicas. Estas, silenciosas, decorrentes de repetidas exposições à agrotóxicos ao longo do tempo, inclusive a baixas doses, causa danos cumulativos e seu diagnóstico é complexo pela dificuldade em associar causa e efeito.

Evidências apontam que exposição crônica aos agrotóxicos acarreta danos neurológicos, transtornos mentais menores (Faria et al., 2014), problemas na fertilidade, aumento da suscetibilidade às neoplasias e agravos à saúde geral (Rigotto et al., 2013). No estudo prospectivo francês AGRICAN, 273 novos casos de câncer no sistema nervoso central foram diagnosticados após seguimento médio de 5,2 anos de 181.842 agricultores e um aumento de risco foi evidenciado em agricultores que utilizavam pesticidas (Piel et al., 2017). Outro estudo na mesma coorte avaliou, em dezembro de 2011, a incidência de câncer nos participantes registrados entre 2005 e 2007, e evidenciou 11.067 casos (Lemarchand et al., 2017). O potencial carcinogênico de alguns agrotóxicos em humanos também foi evidenciado por International Agency for Research on Cancer (IARC), que classificou o glifosato "provável carcinogênico para humanos" (Grupo 2A) (International Agency for Research on Cancer, 2017).

No Brasil, estima-se que $20 \%$ da população ativa trabalha no campo, sujeita a intoxicações e doenças agudas e crônicas, fatais ou não (Pena, 2019). O sistema de saúde vigente no país, a partir de seus princípios e diretrizes, preconiza a atenção integral à saúde com ações direcionadas aos indivíduos, em conformidade com suas necessidades, evidenciadas pelo contexto social, ambiental e de trabalho no qual estão inseridos. No que tange a saúde do trabalhador, a legislação brasileira prevê uma série de regulamentações referentes à produção, comercialização e uso de agrotóxicos. O Ministério do Trabalho e Emprego (MTE) publicou normativas, entre as quais a Resolução Normativa 31 (NR 31), que trata da segurança e saúde do trabalhador rural, implementa a obrigatoriedade do fornecimento e uso de EPI (Ministério do Trabalho e Emprego, 2005).

A NR 7 institui o PCMSO e determina que trabalhadores rurais expostos aos agrotóxicos realizem exames clínicos e complementares periodicamente (Ministério do Trabalho e Emprego, 1978). Dentre os exames preconizados, a acetilcolinesterase eritrocitária (AchE) é um biomarcador de efeito da exposição crônica aos agrotóxicos carbamatos, organofosforados e organoclorados, a qual deveria ser dosada previamente à exposição e semestralmente (Ministério do Trabalho e Emprego, 1978). Contudo, identifica-se falta de monitoramento em relação ao cumprimento dessas normativas e de acompanhamento do trabalhador no contexto geral de saúde.

Mudanças nas práticas agrícolas, que incluem a educação e a conscientização sobre os riscos para a saúde, podem contribuir com a saúde da população exposta. Nesse sentido, identificar as práticas de trabalho de agricultores que desenvolveram o câncer pode contribuir para o aprimoramento e o cumprimento de políticas públicas específicas, ao encontro da manutenção da saúde do trabalhador rural, prevenção de agravos e danos, muitas vezes irreversíveis, inclusive com redução de gastos relacionados à atenção à saúde, de maior complexidade. Igualmente, os resultados podem mobilizar profissionais de saúde no que tange à implantação de protocolos, estruturação de ações e intervenções de educação em saúde com a população envolvida diretamente com o uso de agrotóxicos, extensivo às famílias e comunidades.

Diante da relevância da temática, o objetivo desta pesquisa é caracterizar indivíduos do meio rural, com câncer, quanto às práticas no uso de agrotóxicos, sintomas físicos, emocionais, de intoxicação e níveis de acetilcolinesterase eritrocitária. 


\section{Metodologia}

Estudo de caráter transversal, quantitativo, descritivo (Estrela, 2018), realizado em um hospital geral porte IV, situado no município de Ijuí - RS, nos setores Centro de Alta Complexidade em Oncologia (CACON) e Banco de Sangue (BS). O CACON dispõe de serviços de quimioterapia, radioterapia e braquiterapia para 1,5 milhões de habitantes adscritos aos 120 municípios da área de abrangência da Região Macromissioneira do Estado, inclui as coordenadorias regionais de saúde (CRS) de Ijuí $\left(17^{\mathrm{a}}\right)$, Cruz Alta $\left(9^{\mathrm{a}}\right)$, Santo Ângelo (12a), Palmeira das Missões $\left(15^{\mathrm{a}}\right)$ e Frederico Westphalen $\left(19^{\mathrm{a}}\right)$.

Esta pesquisa foi aprovada pelo Comitê de Ética em Pesquisa da Universidade de Cruz Alta sob no 2.626.873. A abordagem aos participantes da pesquisa foi realizada por alunos de graduação previamente treinados, em ambiente privativo e observados todos os aspectos éticos preconizados pela Resolução CNS n 466/2012. A coleta de dados ocorreu entre agosto de 2018 e janeiro de 2019, e consistiu na aplicação de um instrumento e uma medida quantitativa/clínica: a) questionário com variáveis de identificação, sociodemográficas e práticas relacionadas ao manuseio de agrotóxicos; b) dosagem sanguínea da acetilcolinesterase eritrocitária. Os dados de identificação e sociodemográficos contêm informações sobre idade, sexo, estado civil, escolaridade, profissão. Quanto às variáveis referentes às práticas de manuseio e exposição a agrotóxicos, todas auto relatadas, compreendem questões abertas e fechadas sobre características da propriedade rural em que vivem, uso dos referidos produtos, equipamentos de proteção e impactos à saúde causados pela exposição.

Além do auto relato de exposição a agrotóxicos, os participantes foram convidados a realizar a dosagem da AchE, receberam uma requisição de exames e compareceram ao laboratório de análises clínicas terceirizado da instituição onde foi realizada a pesquisa, que encaminhou as mesmas para laboratório de apoio. Para obtenção das amostras, coletadas por punção arterial ou venosa, junto aos exames da rotina da oncologia, foram necessários $5 \mathrm{ml}$ de sangue total em anticoagulante ácido etilenodiamino tetra-acético (EDTA) e $1 \mathrm{ml}$ de soro, sem necessidade de jejum prévio. A dosagem foi realizada por método fotométrico, cujo valor de referência é de 10.229 a 23.761 U/L, e o Índice Biológico Máximo Permitido é a redução de 30\% do valor inicial ou pré-exposição (Ministério do Trabalho e Emprego, 1978). Considerou-se critérios de exclusão variáveis de interferência na dosagem do analito, entre as quais: uso de medicamentos inibidores da colinesterase (donepezil, rivastigmina, galantamina); ter doenças que interfiram na dosagem do biomarcador, como hemoglobinúria paroxística noturna, anemias megaloblásticas, estados hemolíticos como talassemias, esferocitose, anemia falciforme ativa, outras hemoglobinopatias e anemias hemolíticas adquiridas; ou, ainda, Doença de Alzheimer ou Mal de Parkinson.

Para grupo controle, diante da indisponibilidade de dados pré-exposição dos participantes da pesquisa, um grupo de indivíduos sadios, sem câncer, residentes na zona urbana, não expostos ocupacionalmente a agrotóxicos (GUSNE), foi recrutado no Banco de Sangue da instituição da pesquisa. Este grupo foi utilizado somente para comparação dos resultados da AchE.

A amostra deste estudo, descrita no Fluxograma 1, é uma subamostra selecionada a partir de dados sociodemográficos referentes à área de moradia e exposição ocupacional a agrotóxicos de 270 indivíduos com câncer, vinculados ao projeto de pesquisa intitulado "Avaliação de pacientes oncológicos e relação com a exposição ocupacional a agrotóxicos".

A amostra foi estratificada em dois grupos: a) GRE - residentes na zona rural com exposição ocupacional atual ou passada a agrotóxicos; b) GRNE - residentes rurais não expostos ocupacionalmente aos referidos produtos. Foi utilizada a classificação estabelecida pelo IBGE, que considera como rural as áreas externas ao perímetro urbano das sedes municipais ou distritais e também externas às áreas urbanas isoladas definidas por Lei Municipal (Instituto Brasileiro de Geografia e Estatística, 2010).

A análise estatística foi realizada por meio do software Statistical Package for Social Science (SPSS), versão 23.0. A análise das variáveis categóricas (sexo, nível de escolaridade) foi descrita por meio de frequência absoluta e proporções. Variáveis quantitativas (idade, estatura) foram descritas por meio da média e desvio-padrão. A diferença entre os resultados da 
AchE foi realizada com a aplicação do teste da ANOVA, seguido do teste $t$ de student para amostras independentes. Para todos os testes, considerou-se como diferença estatisticamente significativa valor de $\mathrm{p}<5 \%(\mathrm{p}<0,05)$.

Fluxograma 1. Composição da amostra de participantes da pesquisa com pacientes oncológicos em um centro de oncologia.

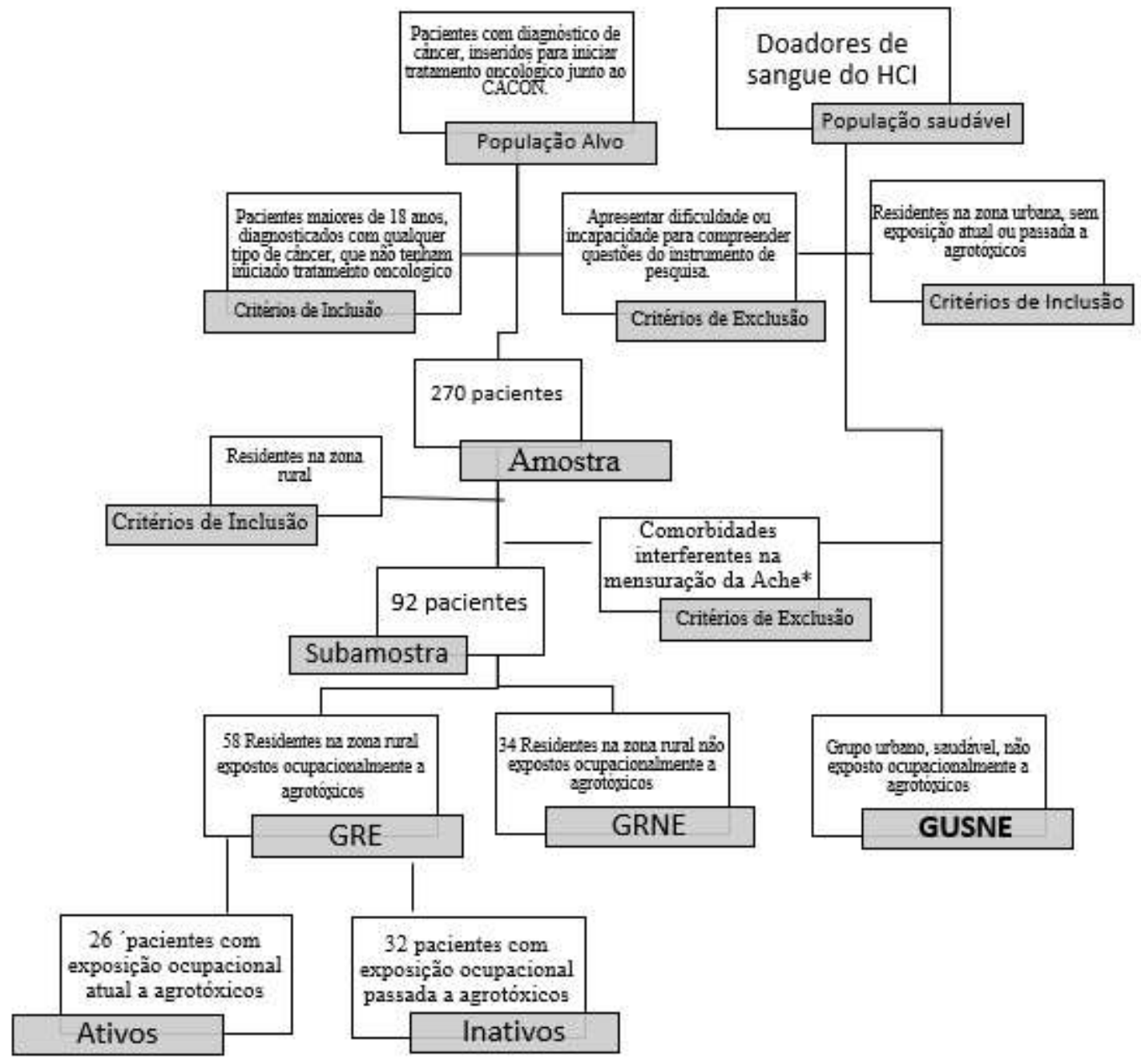

GRE = grupo rural exposto ocupacionalmente a agrotóxicos; GRNE = grupo rural não exposto ocupacionalmente a agrotóxicos; GUSNE = grupo urbano, saudável, não exposto ocupacionalmente a agrotóxicos. Fonte: Dados da pesquisa, Montagner SED (2019).

\section{Resultados}

Participaram do estudo 92 indivíduos, dos quais 58 (63,0\%) relatam ter exposição ocupacional a agrotóxicos atualmente (44,8\%) ou no passado (55,2\%). Quando indagados sobre sua profissão, 84,8\% afirmam ser agricultores, mais de $60,0 \%$ autônomos e 26,1\% aposentados. Constata-se que a maioria dos participantes é do sexo masculino, demonstrado na Tabela 1, embora no GRNE ele seja minoria. Prevalece a baixa escolaridade entre os participantes da pesquisa. 
Tabela 1. Perfil sociodemográfico de trabalhadores e residentes rurais diagnosticados com câncer e assistidos em um CACON, n = 92, Ijuí, RS, Brasil, 2019.

\begin{tabular}{|c|c|c|c|c|}
\hline Variáveis & & $\begin{array}{c}\text { GRE } \\
\text { n (\%) }\end{array}$ & $\begin{array}{l}\text { GRNE } \\
\text { n }(\%)\end{array}$ & $\begin{array}{l}\text { Total } \\
\text { n }(\%)\end{array}$ \\
\hline \multirow{2}{*}{ Sexo } & Feminino & $14(33,3)$ & $28(66,6)$ & $42(45,7)$ \\
\hline & Masculino & $44(88,0)$ & $6(12,0)$ & $50(53,3)$ \\
\hline \multirow{7}{*}{ Idade } & 18 a 30 & $1(1,7)$ & $3(8,8)$ & $4(4,5)$ \\
\hline & 31 a 40 & $1(1,7)$ & - & $1(1,1)$ \\
\hline & 41 a 50 & $10(17,2)$ & $5(14,7)$ & $15(16,3)$ \\
\hline & 51 a 60 & $11(19,0)$ & $9(26,5)$ & $20(21,7)$ \\
\hline & 61 a 70 & $24(41,4)$ & $9(26,5)$ & $33(35,9)$ \\
\hline & 71 a 80 & $7(12,1)$ & $6(17,6)$ & $13(22,4)$ \\
\hline & 81 a 90 & $4(6,9)$ & $2(5,9)$ & $6(6,5)$ \\
\hline \multirow{4}{*}{ Estado civil } & Solteiro & $5(8,6)$ & $3(9,1)$ & $8(8,7)$ \\
\hline & Casado & $45(77,6)$ & $23(67,6)$ & $68(73,9)$ \\
\hline & Separado & $1(1,7)$ & $2(6,1)$ & $3(3,26)$ \\
\hline & Viúvo & $7(12,1)$ & $6(18,2)$ & $13(14,1)$ \\
\hline \multirow{7}{*}{ Escolaridade } & Ensino fundamental completo & $3(5,2)$ & $2(6,8)$ & $5(5,4)$ \\
\hline & Ensino fundamental incompleto & $44(75,9)$ & $27(79,4)$ & $71(77,2)$ \\
\hline & Ensino médio completo & $6(10,3)$ & $2(6,8)$ & $8(8,7)$ \\
\hline & Ensino médio incompleto & $1(1,7)$ & - & $1(1,1)$ \\
\hline & Ensino superior completo & - & $1(3,4)$ & $1(1,1)$ \\
\hline & Ensino superior incompleto & - & $1(3,4)$ & $1(1,1)$ \\
\hline & Sem instrução & $4(6,9)$ & $1(3,4)$ & $5(5,4)$ \\
\hline \multirow{2}{*}{ Profissão } & Agricultor & $53(57,6)$ & $25(27,2)$ & $78(84,8)$ \\
\hline & Outras & $5(5,4)$ & $9(9,8)$ & $14(15,2)$ \\
\hline \multirow{3}{*}{ Atividade } & Autônomo & $41(70,7)$ & $19(55,9)$ & $60(65,2)$ \\
\hline & Empregado & $1(1,7)$ & $1(2,9)$ & $2(2,2)$ \\
\hline & Residente/Familiar & $16(27,6))$ & $14(41,2)$ & $30(32,6)$ \\
\hline
\end{tabular}

GRE = grupo rural exposto ocupacionalmente a agrotóxicos; GRNE = grupo rural não exposto ocupacionalmente a agrotóxicos. Fonte: Dados da pesquisa, Montagner SED (2019).

A média de idade do GRE é 61,65 \pm 13,31 anos, e do GRNE é 59,26 \15,02 anos, com mínima de 20 e 19 e máxima de 90 e 87 anos, respectivamente. Quanto à moradia, todos os participantes residem na zona rural, em média há 48,65 \pm 23,66 anos, a maioria em terras próprias e 42,4\% deles em municípios adscritos à $12^{\text {a }}$ Coordenadoria Regional de Saúde (CRS). Quanto às propriedades rurais nas quais residem, predominam áreas de até 25 hectares (76,1\%), e os agrotóxicos são utilizados em mais da metade delas (Tabela 2). 
Tabela 2. Caracterização da propriedade rural onde residem os indivíduos rurais com câncer, n = 92, Ijuí, RS, Brasil, 2019.

\begin{tabular}{|c|c|c|c|c|}
\hline & & $\begin{array}{l}\text { GRE } \\
\text { n (\%) }\end{array}$ & $\begin{array}{l}\text { GRNE } \\
\text { n (\%) }\end{array}$ & Total \\
\hline \multirow{2}{*}{ Uso de agrotóxicos na propriedade } & Sim & $39(67,2)$ & $16(47,1)$ & $55(59,8)$ \\
\hline & Não & $19(32,8)$ & $18(52,9)$ & $37(40,2)$ \\
\hline \multirow{3}{*}{ Número de pessoas na residência* } & 1 a 3 & $28(48,3)$ & $25(73,5)$ & $53(57,6)$ \\
\hline & 4 a 6 & $18(31,0)$ & $7(20,6)$ & $25(27,2)$ \\
\hline & 7 ou mais & $3(5,2)$ & - & $3(3,3)$ \\
\hline \multirow{4}{*}{$\begin{array}{l}\text { Distância da residência até a lavoura } \\
\text { mais próxima** }\end{array}$} & Até $50 \mathrm{~m}$ & $26(44,8)$ & $13(38,2)$ & $39(42,4)$ \\
\hline & De 51 a $200 \mathrm{~m}$ & $14(24,1)$ & $4(11,8)$ & $18(19,6)$ \\
\hline & De 201 a $500 m$ & $4(6,9)$ & $2(5,9)$ & $6(6,5)$ \\
\hline & Mais de $501 \mathrm{~m}$ & $2(3,4)$ & $3(8,8)$ & $5(5,4)$ \\
\hline \multirow{4}{*}{ Hectares } & 1 a 25 & $46(79,3)$ & $24(70,6)$ & $70(76,1)$ \\
\hline & 26 a 50 & $5(8,6)$ & $2(5,9)$ & $7(7,6)$ \\
\hline & Acima de 201 & $1(1,7)$ & $1(2,9)$ & $2(2,2)$ \\
\hline & Não sabe & $6(10,3)$ & $7(20,6)$ & $13(14,1)$ \\
\hline \multirow{3}{*}{ Terra } & Própria & $42(72,4)$ & $27(79,4)$ & $69(75,0)$ \\
\hline & Arrendada & $4(6,9)$ & - & $4(4,3)$ \\
\hline & Própria e arrendada & $4(6,9)$ & - & $4(4,3)$ \\
\hline Horta & Sim & $57(98,3)$ & $30(88,2)$ & $87(94,6)$ \\
\hline \multirow{2}{*}{ Uso de agrotóxicos nas hortaliças } & Sim & $4(7,0)$ & $2(6,6)$ & $6(6,9)$ \\
\hline & Não & $53(93,0)$ & $28(93,4)$ & $81(93,1)$ \\
\hline
\end{tabular}

*11 indivíduos não responderam; **24 indivíduos não responderam. Fonte: Dados da pesquisa, Montagner SED (2019).

Ainda em relação à Tabela 2, evidencia-se a proximidade entre as lavouras e residências e, em 94,6\% delas, mantémse o cultivo de hortaliças, a grande maioria sem consumo de agrotóxicos para esta finalidade. Predominam residências com até 3 moradores e constata-se que, entre os participantes da pesquisa, 87,0 \% são filhos de pai agricultores e $82,6 \%$ de mãe agricultora, e mais da metade deles relatam histórico de câncer em familiares.

Os dados da presente pesquisa mostram que, em média, 1,3 pessoas manuseiam agrotóxicos em cada propriedade e, dentre os produtos utilizados, constatou-se 22 apresentações comerciais, formuladas a partir de 24 ingredientes ativos. Destes, $11(50,0 \%)$ são classificados como extremamente tóxicos (classe I) e altamente tóxicos (classe II) para humanos. Constatou-se menor frequência de relatos de inseticidas organofosforados e organoclorados, entre os quais metidationa, paration e acefato; a maioria dos participantes se reportaram somente à classe do produto, e herbicida foi a mais frequente, relatada também como secante e glifosato.

Sequencialmente, na Tabela 3, são explicitadas as culturas produzidas pelos respectivos grupos de indivíduos que residem no meio rural, expostos e não expostos ocupacionalmente a agrotóxicos. Nesta, constata-se maior frequência de hortaliças entre as culturas mais produzidas. 
Tabela 3. Culturas produzidas nas propriedades agrícolas onde residem os indivíduos rurais com câncer, $n=92$, Ijuí, RS, Brasil, 2019.

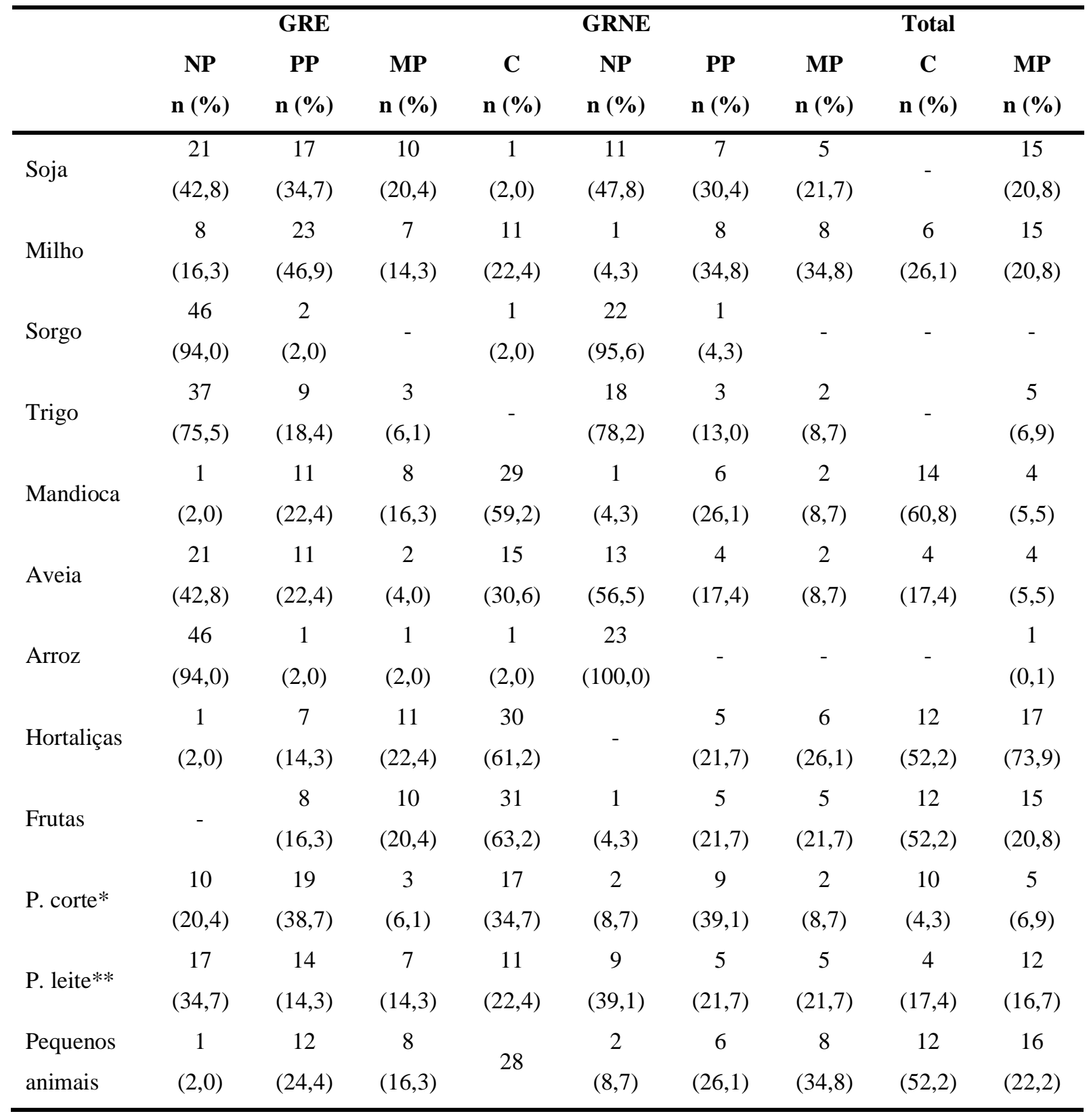

$\mathrm{NP}=$ não produzido $\mathrm{PP}=$ pouco produzido; $\mathrm{MP}=$ muito produzido $; \mathrm{C}=$ consumo.

Porcentagens de respostas válidas: 20 indivíduos não responderam, 9 do GRE e 11 do GRNE.

*Pecuária de corte; **Pecuária de leite.

Fonte: Dados da pesquisa, Montagner SED (2019).

Ainda em relação aos dados contidos na Tabela 3, verifica-se que a maioria dos participantes afirmou não produzir arroz, sorgo e trigo, e mais de 40,0\% deles não cultiva soja e aveia. No que se refere ao GRNE, evidencia-se maiores percentuais de produção de pequenos animais, milho e pecuária de leite, o que diverge do GRE, hortaliças, frutas e soja.

Em média, os participantes desta pesquisa atuam na área agrícola há 42 anos, com amplituse de 2 meses à 88 anos. As práticas de trabalho relacionadas ao uso de agrotóxicos entre os participantes da pesquisa são apresentados na Tabela 4. Nesta, constata-se que o armazenamento dos referidos produtos, com maior frequência, é realizado em ambiente adequado; quanto à aquisição dos mesmos, mais de 40,0\%, ocorre em cooperativas, sem receituário agronômico em pelo menos 19,0\% das propriedades. Quanto aos equipamentos utilizados na aplicação de agrotóxicos, o uso do costal e trator sem cabine é frequente, 
e a principal atividade de contato é o preparo da calda e aplicação na lavoura, preferencialmente no início da manhã e final da tarde.

Os dados contidos na Tabela 4 evidenciam a falta de orientação técnica, relatada por mais da metade dos participantes da pesquisa. Não houveram relatos de instrução por parte de órgãos públicos da agricultura ou da área da saúde. Com relação aos cuidados no uso de agrotóxicos, constata-se que mais de 50\% afirmaram lavar as mãos e rosto após o uso, além de observar posição do vento antes da aplicação dos respectivos produtos. Evitar o consumo de alimentos e não fumar durante o uso é prática relatada pela metade dos indivíduos expostos ocupacionalmente. A minoria não faz a leitura atenta do rótulo antes do preparo e aplicação do agrotóxico. Quanto aos equipamentos de proteção individual (EPI), constata-se que mais da metade refere a utilização de botas sempre que em contato com agrotóxicos; protetor solar foi referido em menor frequência. Nenhum dos participantes referiu o uso de avental sempre que tem contato com agrotóxicos.

Tabela 4. Práticas de trabalho no uso de agrotóxicos por indivíduos com câncer residentes na área rural e expostos ocupacionalmente a agrotóxicos (GRE), n = 58, Ijuí, RS, Brasil, 2019.

\begin{tabular}{|c|c|}
\hline Práticas de trabalho & n(\%) \\
\hline Manipulação de agrotóxicos & 58 \\
\hline Sim, ativo & $26(44,8)$ \\
\hline Sim, inativo & $32(55,2)$ \\
\hline Armazenamento de agrotóxicos* & 45 \\
\hline Depósito específico trancado & $20(44,4)$ \\
\hline Galpão & $17(37,8)$ \\
\hline Não armazena & $8(17,8)$ \\
\hline Local de aquisição de agrotóxicos & $48^{\mathrm{a}}$ \\
\hline Revenda agrícola & $15(25,9)$ \\
\hline Cooperativa & $27(46,6)$ \\
\hline Vendedores & $2(3,4)$ \\
\hline Agropecuária & $1(1,7)$ \\
\hline Revenda e cooperativa & $3(5,2)$ \\
\hline Aquisição com receituário agronômico & $37^{\mathrm{a}}$ \\
\hline Sim & $26(44,8)$ \\
\hline Não & $11(19,0)$ \\
\hline \multicolumn{2}{|l|}{ Maquinários disponíveis para aplicação ${ }^{\mathbf{b}}$} \\
\hline Costal & $21(36,2)$ \\
\hline Trator sem cabine & $23(39,7)$ \\
\hline Trator gabinado & $7(12,0)$ \\
\hline Pulverizador & $26(44,8)$ \\
\hline Pulverização aérea & $1(1,7)$ \\
\hline Arado & $1(1,7)$ \\
\hline \multicolumn{2}{|l|}{ Recebe orientação } \\
\hline Sim & $28(48,3)$ \\
\hline
\end{tabular}




\section{Quem orienta}

Vendedor

$3(10,7)$

Técnico da cooperativa

$13(46,4)$

Agrônomo

$10(35,7)$

Vendedor, técnico da Emater e vizinhos

$2(7,1)$

\section{Atividade de contato ${ }^{b}$}

Transporte e armazenamento

$21(36,2)$

Preparo da calda

$27(46,5)$

Aplicação

$27(46,5)$

Limpeza de equipamentos

$23(39,6)$

Tratamento de sementes

$18(31,0)$

Descarte de embalagens

$15(25,8)$

Colheita

$15(25,8)$

Manuseio de roupa contaminada

$19(32,7)$

Entra na lavoura

$11(19,0)$

\section{Turno de aplicação ${ }^{b}$}

Início da manhã

Início da tarde

Final da tarde

$34(58,6)$

Noite/madrugada

$1(1,7)$

Não observa horário

$2(3,4)$

Cuidados no manuseio e aplicação de agrotóxicos

Lavar os EPI's após a aplicação

$16(27,6)$

Lavar as roupas contaminadas separadas das demais da família

$22(37,9)$

Leitura atenta do rótulo antes do preparo e aplicação do agrotóxico

$13(22,4)$

Aplicar agrotóxicos conforme instruções do fabricante

Nunca entrar na plantação recém tratada

Observar a posição do vento antes de aplicar o produto

$32(55,2)$

Lavar as mãos e rosto após o uso

$34(58,6)$

Tomar banho completo após o uso

$21(36,2)$

Trocar a roupa após o uso de agrotóxicos

$28(48,3)$

Evitar comer ou fumar enquanto manuseia agrotóxicos

$29(50,0)$

Lavar equipamentos próximo à casa ${ }^{\mathrm{d}}$

$24(41,4$

Nunca entrar na plantação recém tratada ${ }^{\mathrm{d}}$

$21(36,2$

Uso de outros produtos químicos**

Não

$22(42,3)$

Até 2 dias/mês

$19(36,5)$

De 3 a 10 dias/mês

De 11 a 20 dias/mês

Mais de 21 dias/mês 


\section{Uso de EPIs, sempre que manuseia agrotóxico ${ }^{\mathrm{e}}$}

Botas

Chapéu

Luvas

$19(32,7)$

Macacão

Máscara

Óculos

Protetor Solar

$11(18,9)$

$\mathrm{a}=$ referente aos agricultores que responderam à questão; $\mathrm{b}=$ resposta múltipla; $\mathrm{c}=$ referentes aos agricultores que responderam "sempre"; $d=$ referentes aos agricultores que responderam "nunca"; $\mathrm{e}=$ avental não foi relatado pelos participantes. *13 indivíduos não responderam; **6 indivíduos não responderam. Fonte: Dados da pesquisa, Montagner SED (2019).

Quando questionados acerca de sintomas físicos e emocionais, poucos participantes afirmaram percebê-los no seu contato com agrotóxicos. A partir dos dados contidos na Tabela 5, evidencia-se a dor de cabeça como sintoma físico mais associado ao uso de agrotóxicos, e a maioria destes sintomas são mais frequentes no GRE. Constata-se, ainda, baixa frequência de sintomas emocionais relacionados ao uso de agrotóxicos em ambos os grupos, e maior percepção de risco do agrotóxico pelos integrantes do GRE.

Tabela 5. Percepção de risco, sintomas físicos, emocionais, e intoxicações por agrotóxicos nos participantes da pesquisa, $\mathrm{n}=$ 92, Ijuí, RS, Brasil, 2019.

\begin{tabular}{|c|c|c|c|c|c|c|c|}
\hline Variáveis & $\begin{array}{l}\text { GRE } \\
\text { n (\%) }\end{array}$ & $\begin{array}{l}\text { GRNE } \\
\text { n(\%) }\end{array}$ & $\begin{array}{l}\text { Total } \\
\text { n }(\%)\end{array}$ & & $\begin{array}{l}\text { GRE } \\
\text { n (\%) }\end{array}$ & $\begin{array}{l}\text { GRNE } \\
\text { n }(\%)\end{array}$ & $\begin{array}{l}\text { Total } \\
\text { n }(\%)\end{array}$ \\
\hline \multicolumn{8}{|c|}{ Sintomas físicos associados ao contato com agrotóxicos } \\
\hline Dor cabeça & $14(24,1)$ & $7(20,6)$ & $21(22,8)$ & Salivação & $4(6,9)$ & $1(2,9)$ & $5(5,4)$ \\
\hline Náusea e vômito & $7(12,1)$ & $5(8,6)$ & $12(20,7)$ & $\begin{array}{l}\text { Chiado e falta } \\
\text { de ar }\end{array}$ & $3(5,2)$ & $1(2,9)$ & $4(4,3)$ \\
\hline Visão turva & $2(3,4)$ & $2(5,8)$ & $4(4,3)$ & Diarreia & $1(1,7)$ & - & $1(1,1)$ \\
\hline Tontura & $7(12,0)$ & $2(5,8)$ & $9(9,8)$ & Tosse seca & $2(3,4)$ & $1(2,9)$ & $3(3,3)$ \\
\hline Suor & $2(3,4)$ & $1(2,9)$ & $3(3,3)$ & Tremores & $2(3,4)$ & - & $2(2,2)$ \\
\hline $\begin{array}{l}\text { Má digestão e dor } \\
\text { abdominal }\end{array}$ & $4(6,9)$ & $2(5,8)$ & $6(6,5)$ & Epífora & $2(3,4)$ & $2(5,8)$ & $4(4,3)$ \\
\hline Lesões pele & $1(1,7)$ & $1(2,9)$ & $2(2,2)$ & Irrit. olhos & $8(13,8)$ & $2(5,8)$ & $10(10,9)$ \\
\hline F. membros & - & $2(5,8)$ & $2(2,2)$ & & & & \\
\hline
\end{tabular}

Sintomas emocionais associados ao contato com agrotóxicos

Dificuldade de

$\begin{array}{lccclccc}\text { concentração } & 1(1,7) & 1(2,9) & 2(2,2) & \text { Cansaço mental } & 5(8,6) & 1(2,9) & 6(6,5) \\ \text { Desânimo } & 5(8,6) & 1(2,9) & 6(6,5) & \text { Agitação } & 5(8,6) & 1(2,9) & 6(6,5) \\ \text { Insônia } & 1(1,7) & 2(5,8) & 3(3,3) & \text { Irritação } & 5(8,6) & 1(2,9) & 6(6,5) \\ & & & & \text { Tristeza } & 1(1,7) & - & 1(1,1)\end{array}$




\section{Risco que atribui ao seu contato com agrotóxico}

Muito perigoso

Perigoso

Pouco perigoso

Não é perigoso

Intoxicação por uso de agrotóxicos

$\operatorname{Sim}$

\section{Quando}

Nos últimos três meses

Há seis meses

Há 1 ano

Não lembra

Realizou exames para monitorar exposição a agrotóxicos?

$\operatorname{Sim}$

Não

Não sabe

Dosagem de Acetilcolinesterase eritrocitária na pesquisa

$\begin{array}{ccc}31(53,4) & 15(44,1) & 46(50,0) \\ 20(34,5) & 11(32,3) & 31(33,7) \\ 3(5,2) & - & 3(3,3) \\ - & 3(8,8) & 3(3,3)\end{array}$

$9(15,5) \quad 3(33,3) \quad 12(13,0)$

$\begin{array}{ccc}1(1,7) & - & 1(1,1) \\ 1(1,7) & - & 1(1,1) \\ 1(1,7) & - & 1(1,1) \\ 6(10,3) & 3(8,8) & 9(9,7)\end{array}$

$\begin{array}{ccc}4(6,9) & 1(2,9) & 5(5,4) \\ 50(86,2) & 27(79,4) & 77(83,7) \\ 4(6,9) & 6(17,6) & 10(10,9)\end{array}$

$20(34,5) \quad 6(17,6) \quad 26(28,3)$

F. membros $=$ formigamento de membros; Irrit. olhos = irritação nos olhos. Fonte: Dados da pesquisa, Montagner SED (2019).

Ainda em relação aos dados da Tabela 5, evidencia-se baixo percentual de intoxicação entre os participantes da pesquisa que, em sua maioria, nunca realizaram exames de monitoramento da exposição a agrotóxicos. Dentre os 4 indivíduos do GRE que relataram a realização de exames, 2 o fizeram por ocasião do episódio de intoxicação, e foram os únicos casos que foram atendidos por profissionais de saúde. Na presente pesquisa, 26 (28,3\%) participantes realizaram a dosagem sanguínea da acetilcolinesterase eritrocitária. A média dos resultados do respectivo analito no GRE foi de $14.510 \pm 4106 \mathrm{U} / \mathrm{L}$, com mínima de 4.348 U/L e máxima de 24250 U/L; no GRNE, foi $13.358 \pm 4.723$ U/L, a mínima 7.023 U/L e máxima 20.358 U/L. Não houve diferença estatisticamente significativa entre os dois grupos, nem quando comparados ao grupo de indivíduos urbanos e sadios, cuja média foi de 14.015 × 2942 U/L, com mínima de 9960 U/L e máxima de 18.773 U/L.

Como explicitado na Tabela 4, entre os indivíduos do GRE, há um percentual de 44,8\% que relata exposição atual a agrotóxicos. Evidencia-se que a média de AchE neste grupo ativo foi de $13.364 \pm 3.571 \mathrm{U} / \mathrm{L}$, e apresenta diferença estatisticamente significativa tanto quando comparada à média do grupo inativo, que foi $17.251 \pm 3.869 \mathrm{U} / \mathrm{L}$ ( $\mathrm{p}=0,025$ ), como quando comparada à média do GUSNE $(\mathrm{p}=0,043)$. Ainda em relação aos resultados da AchE, constatou-se que a média no GRNE não apresentou diferença estatisticamente significativa comparado ao GRE ativo ( $p=0,319)$, enquanto houve significância estatística comparado ao GRE inativo ( $\mathrm{p}=0,026)$.

\section{Discussão}

O predomínio de homens entre os expostos ocupacionalmente a agrotóxicos no meio rural foi evidenciado neste e em outros estudos (Moura et al., 2014; Pasiani et al., 2012). A baixa escolaridade foi frequente no presente estudo, resultado 
semelhante aos de Kongtip et al. (2018) e Naidoo et al. (2010), e com implicações na forma de trabalho, nas condições de saúde e de doença dos respectivos trabalhadores (Silva et al., 2014).

A maior frequência de idade dos indivíduos rurais com câncer ocorre entre 51 e 70 anos, ao encontro de Depczynski et al. (2018). A média de idade foi menor no GRNE, no qual predomina mulheres, ao encontro de Ramírez-Santa et al. (2018), e este resultado era esperado uma vez que as atividades rurais no Brasil relacionadas à agricultura são exercidas predominantemente por homens.

Entre as atividades relatadas pelos participantes do estudo expostos a agrotóxicos, com maior frequência estão o preparo da calda e a aplicação dos produtos na lavoura. Estudo evidenciou maior risco de câncer de bexiga em trabalhadores agrícolas da coorte AGRICAN, que mostrou uma relação exposição-resposta decorrentes de anos de atuação dos respectivos trabalhadores (Boulanger et al., 2017). Os autores se reportam aos riscos aumentados, mesmo não estatisticamente significativos, nos participantes que realizavam tratamento de sementes $(H R=1,24)$ ou tarefas relacionadas à reentrada na lavoura (HR = 1,63) (Boulanger et al., 2017).

Os resultados do estudo ora analisado mostram predomínio de pequenas propriedades rurais, próximas às lavouras, com poucos moradores nas residências. A caracterização das propriedades rurais nas quais residem os participantes da pesquisa, associada ao perfil ocupacional dos mesmos, maioria agricultores autônomos, evidencia que esta população está inserida no contexto da agricultura familiar (Abreu \& Alonzo, 2016). Esta, trata-se do cultivo da terra por pequenos proprietários rurais, com mão de obra essencialmente familiar (Souza Filho et al., 2004). O contexto da agricultura familiar pode justificar a falta de treinamento relatada pelos participantes e o uso inadequado de EPI'S, uma vez que a fiscalização é ineficiente ou inexistente.

O perfil de agricultura familiar reflete as culturas produzidas nas propriedades agrícolas em questão. Neste contexto, as culturas de arroz, trigo e soja são relatados por grande parte dos participantes como não produzidos, independente do grupo. No GRE, as maiores frequências relatadas como "muito produzido" se referem à hortaliças e frutas, enquanto no GRNE, milho, pequenos animais e hortaliças. Estes resultados podem justificar a diferença no percentual de uso de agrotóxicos nas propriedades de cada grupo. Reitera-se que, embora os indivíduos integrantes do GRNE não se exponham ocupacionalmente a agrotóxicos, $47,1 \%$ deles relatam uso dos referidos produtos em suas propriedades, o que pode potencializar a exposição ambiental e/ou alimentar.

Exposição ambiental, ingestão involuntária de água e de alimentos contaminados ou, ainda, manuseio de roupas contaminadas, que foi relatada por mais de 30,0\% dos participantes da pesquisa, compreendem a exposição acidental referida por Neves e Bellini (2013). Sujeitos a ela estão, também, os familiares dos trabalhadores, expostos a partir da lavagem de roupas contaminadas junto às demais da família ou quando equipamentos de pulverização de agrotóxicos são lavados próximos às residências. Menos de 45,0\% dos participantes do GRE referem adotar estes cuidados. A observação da posição do vento e do turno de aplicação dos agrotóxicos foi relatada por mais da metade da amostra e é importante para reduzir a exposição humana em regiões tropicais, devido ao aumento da volatilidade dos produtos (Silva et al., 2005).

A diversidade de culturas já abordada implica na diversidade de fórmulas químicas empregadas. Na pesquisa ora analisada, o glifosato foi relatado com maior frequência, em ambos os grupos. Trata-se de um herbicida organofosforado, cujo consumo mundial aumentou drasticamente após a liberação dos organismos geneticamente modificados e, recentemente, foi classificado pela IARC como "provável carcinogênico para humanos" (IARC, 2017). Os agrotóxicos citados com menor frequência, entre os quais organofosforados e organoclorados, assemelham-se aos encontrados por Manyilizu et al. (2017). Chama atenção a frequência com que os agricultores se referem à classe dos produtos, e não aos seus nomes comerciais ou princípios ativos, o que reporta ao baixo percentual de leitura do rótulo evidenciado neste estudo. Esse resultado vai de encontro aos achados de Santana et al. (2016), os quais evidenciaram percentuais mais elevados. 
Ainda em relação ao déficit de conhecimento destes indivíduos acerca dos referidos produtos, aliado à baixa escolaridade e insuficiente orientação técnica demonstrada na pesquisa ora analisada, vão ao encontro de estudo por Abreu e Alonzo (2016) e Dasgupta et al., (2005). Eles afirmam que a indisponibilidade de engenheiros agrônomos e técnicos agrícolas junto às pequenas propriedades rurais compromete práticas corretas e seguras no uso de agrotóxicos. Neste contexto, a cooperativa, onde mais de 40,0\% dos indivíduos do GRE adquirem os insumos, é referência para esta população no que tange à orientação técnica. Não houve relatos de orientação por parte de órgãos públicos e instituições de saúde, o que já foi evidenciado por estudo no Sul do Brasil, e demonstra lacuna em ações de prevenção a agravos na população rural por parte de equipes de saúde (Machado et al., 2017).

Constata-se alto índice de abstenção dos participantes em responder à questão sobre o uso de receituário agronômico. Abreu e Alonzo (2016) evidenciaram falta de conhecimento sobre alguns termos de uso na agricultura, o que pode acontecer quando o indivíduo manipula os produtos mas não detém o conhecimento acerca de toda a cadeia de produção, inclusive a aquisição dos produtos. Da mesma forma, 22,4\% dos participantes não responderam sobre o armazenamento dos produtos em suas propriedades, o que pode ser justificado tanto pelo armazenamento incorreto, ao encontro dos achados de Santana et al. (2016); quanto pelo medo de explicitar essa informação, inclusive por receio de furtos.

Diretrizes legais balizam a publicação de manuais de boas práticas de uso de agrotóxicos, que contenham orientações quanto às ações no âmbito agrícola, com vistas à segurança do trabalho no campo (Ministério do Trabalho e Emprego, 2002). Neste contexto, o cumprimento de boas práticas de uso de agrotóxicos poderia ser melhor evidenciado, o que não ocorreu nesta pesquisa. Quanto ao uso de EPIs, com exceção da bota, nenhum outro equipamento é utilizado sempre que em contato com agrotóxicos por mais de $40 \%$ dos indivíduos, o que demonstra uso inadequado, ao encontro de outros estudos com trabalhadores rurais (Abreu \& Alonzo, 2016; Instituto Brasileiro de Geografia e Estatística, 2009; Manyilizu et al., 2017; Pasiani et al., 2012).

A lavagem de EPIs após o uso de agrotóxicos foi mencionada por menos de 30,0\% dos participantes e o hábito de tomar banho após a pulverização é relatado com menor frequência que trocar a roupa após o uso, o que demonstra prática de risco. Neste sentido, Kongtip et al. (2011) evidenciaram média urinária de dietil fosfato (DEP), um inseticida organofosforado, significativamente menor em agricultores que tomaram banho imediatamente após a pulverização, comparado aos que não tomaram. Em estudo com trabalhadores rurais na Tailândia, Kongtip et al. (2018) constataram que produtores de hortaliças usaram menos luvas e tiveram menor frequência para todos os comportamentos positivos de prevenção de exposição a agrotóxicos; e maior frequência de câncer foi constatada no grupo de produtores de flores e hortaliças em relação aos de arroz.

Ainda em relação ao uso de EPIs, autores pontuam que a proteção ofertada pelos mesmos pode chegar a $96 \%$ de redução da exposição (Soares et al., 2005; Ramos, 2006) e que depende do uso correto. Este está atrelado à conscientização e percepção do risco pelo trabalhador (Barroso \& Wolff, 2009). A adesão às práticas de segurança por trabalhadores rurais é dificultada pela concepção de que o risco é inerente à atividade agrícola. Considera-se que esta questão é complexa, requer atenção, uma vez evidenciada a utilização frequente de equipamentos costais e tratores sem cabine pelos participantes da pesquisa, semelhante aos achados de Pasiani et al. (2012), característicos da agricultura familiar.

Pensa-se também que, para esses trabalhadores, a modernização implica em custos, o que inviabiliza a aquisição de equipamentos mais seguros para o exercício de suas atividades, em especial a aplicação de agrotóxicos. Diante desta realidade vivenciada por eles, emerge a necessidade do uso de outras estratégias, tais como ações e intervenções educacionais em saúde. Essa reflexão vai ao encontro dos elementos que integram a tríade "Three Es", que se refere a "Educação, Engenharia e Aplicação", utilizada por pesquisadores de saúde e segurança agrícola em abordagens de prevenção de riscos ao trabalhador rural (Sorensen et al., 2017). 
No estudo ora analisado, evidenciou-se baixa frequência de relatos de sintomas físicos que eles associam ao contato com agrotóxicos, de encontro a Manyilizu et al. (2017), que demonstrou associação significativa entre altas frequências de sintomas auto relatados e práticas inseguras de uso de agrotóxicos, como uso inadequado de EPIs. Outra investigação evidenciou maior frequência de dor de cabeça entre produtores de arroz e hortaliças (Kongtip et al., 2018). Quanto aos sintomas emocionais relatados, a frequência foi ainda menor, ao encontro de Morin e Stumm (2018).

No que tange às intoxicações, evidenciou-se baixa frequência de episódios auto relatados e maior frequência de relatos por quem tem ou teve contato direto com agrotóxicos, ao encontro de Faria et al. (2004). O reduzido número de encaminhamentos destes casos à equipe de saúde remete à Organização Mundial da Saúde (OMS), ao afirmar que, para cada caso notificado de intoxicação por agrotóxicos, são estimados 50 casos subnotificados (Carneiro et al., 2015). Neste contexto, a realização de exames para confirmação dos casos é fundamental. A AchE é um marcador de efeito da intoxicação a organofosforados e carbamatos, amplamente utilizado em pesquisas com trabalhadores rurais (Pasiani et al., 2012; RamírezSantana et al., 2018), entretanto, o presente estudo evidenciou a falta de monitoramento de trabalhadores expostos a agrotóxicos, uma vez que a minoria relatou já ter realizado algum exame para esta finalidade.

Neste estudo, utilizou-se a dosagem da AchE com o intuito de reafirmar o relato de exposição dos participantes da pesquisa. Constatou-se diferença estatisticamente significativa entre a média da AchE do GRE ativo e do GUSNE, achado semelhante ao encontrado por Silvério et al. (2017). Estes autores, além de demonstrar diferença significativa na redução da atividade da AchE em grupo de trabalhadores expostos ocupacionalmente a organofosforados em relação ao grupo não exposto, evidenciaram que a redução da atividade da AchE está associada à alteração do teste de micronúcleos ( $\mathrm{p}<0,01)$, o que sugere risco aumentado de efeitos genotóxicos naqueles indivíduos expostos a pesticidas organofosforados.

A exposição excessiva a organofosforados e carbamatos e consequente efeito adverso ou intoxicação são caracterizados a partir da redução de $30 \%$ da atividade da enzima em relação ao valor basal (Hermes Pardini, 2018). No presente estudo, embora com diferença estatisticamente significativa, a redução da média de AchE do GRE ativo foi inferior a 5\% da média do grupo controle. Estes resultados vão de encontro aos de Santana et al. (2016), que identificaram 25\% e 23\% de inibição da AchE em indivíduos rurais expostos ambientalmente e ocupacionalmente, respectivamente, comparados aos valores basais individuais. Os autores evidenciaram, ainda, reduções significativas em outros biomarcadores, e os resultados indicaram mais pessoas em risco na população rural geral do que entre trabalhadores agrícolas no instante em que a amostragem foi realizada, porém não analisaram a influência de práticas de trabalho individuais ou uso de equipamentos de proteção nas atividades dos respectivos biomarcadores.

No estudo ora analisado, as médias da AchE do GRE ativo e do GRNE foram muito semelhantes, sem diferença estatisticamente significativa. Este resultado vai ao encontro de Naidoo et al. (2003) que, igualmente, não evidenciou diferença estatisticamente significativa entre grupos de mulheres expostas e não expostas ocupacionalmente a agrotóxicos, e atribuíram o resultado à exposição doméstica e ambiental do grupo não exposto. Outro estudo constatou inibição da respectiva enzima nos residentes em ambientes de agricultura familiar e possível risco de exposição secundária a agrotóxicos (Pasiani et al., 2012).

A média da AchE no GRE ativo é 22,5\% menor comparada ao GRE inativo, com diferença estatisticamente significativa. O tempo de afastamento dos indivíduos do GRE inativo ao contato com agrotóxicos não foi objeto deste estudo, mas é requerido, entre outras informações adicionais, para elucidação do achado. O efeito de reinicialização abordado por Pasiani et al. (2012) poderia explicar este resultado. Os referidos autores não evidenciaram diferença estatisticamente significativa em médias de AchE coletadas em trabalhadores rurais nos períodos de exposição e não exposição, e afirmam que o efeito de reinicialização, ou capacidade do corpo se adaptar ao acúmulo de acetilcolina logo após a exposição, possa ter influenciado. 
Foi observada variabilidade dos resultados da AchE nos grupos rurais, refletida nos valores do desvio-padrão. Os valores mínimos encontrados para o analito nos GRE e GRNE, 4.348 e 7.023, respectivamente, encontram-se abaixo do valor de referência. Embora a relação destes resultados com os tipos de câncer evidenciados na amostra não seja objeto deste estudo, observa-se que o menor resultado de AchE encontrado refere-se a um paciente exposto ocupacionalmente a agrotóxicos, com diagnóstico de câncer de próstata. Battisti et al (2011) evidenciaram que a redução da atividade a AchE e o consequente acúmulo de acetilcolina pode atuar como fator de promoção tumoral no câncer de próstata.

Nesse âmbito, a caracterização da exposição a agrotóxicos se constitui em importante desafio diante da disponibilidade limitada de biomarcadores de exposição economicamente acessíveis e do uso de vários tipos diferentes de agrotóxicos. A presença do agente químico ou seus metabólitos detectados em fluído ou tecido humano aufere maior fidedignidade à avaliação da exposição e são usados em pesquisas, como a de Bassig e Lan (2019), na qual ocorreu associação de níveis elevados de dieldrina e metabólitos derivados de clordano e heptacloro com risco de LMA na população norueguesa geral, baseados em amostras coletadas, em média, 17 anos antes do diagnóstico de câncer.

A presente pesquisa permitiu identificar e relacionar aspectos do perfil da população rural com câncer e suas práticas agrícolas, ambas determinantes da condição de saúde destes indivíduos. Os resultados demonstram a necessidade de um olhar atento de profissionais da saúde a esta população, inclusive com vistas à construção de estratégias de educação em saúde para ampliar a segurança no uso de agrotóxicos e, desta forma, prevenir danos à saúde.

\section{Conclusão}

A população rural recentemente diagnosticada com câncer, exposta ocupacionalmente ou não, assistida em um CACON de um hospital geral da região Noroeste do RS é composta de pequenos produtores. Evidencia-se predomínio de agricultura familiar, com destaque para a produção de hortifrutigranjeiros. Os participantes utilizam agrotóxicos com equipamentos que favorecem o contato direto com os respectivos produtos, inclusive com uso inadequado de EPIs.

Considera-se que, por se tratar de pequenos produtores rurais, eles não são contemplados por uma relação formal de trabalho que preconize o monitoramento da exposição ocupacional a agrotóxicos. Além disso, há lacunas referente ao uso seguro destes produtos, provavelmente relacionadas ao baixo nível de escolaridade, o que os tornam mais suscetíveis aos agravos decorrentes da exposição direta e indireta. A análise dos resultados da mensuração da acetilcolinesterase eritrocitária mostrou valores médios normais, porém não permite afirmar a ausência de intoxicação, que requer o uso de exames complementares e específicos.

As evidências referidas no corpo do trabalho quanto à influência da acetilcolina como promotora tumoral em diferentes tipos de câncer, reforçam a necessidade de monitoramento contínuo da população rural exposta a agrotóxicos. Como profissional de saúde, preocupa o fato dos participantes terem consciência do risco e manterem práticas inadequadas de uso de agrotóxicos. Mesmo com diagnóstico recente de câncer, a maioria deles não atribui este desfecho e outros sintomas físicos e emocionais à exposição a agrotóxicos.

Desta forma, tais dados observados no presente estudo servem de subsídio para novos estudos e intervenções nesta população, entre os quais estudos observacionais de acompanhamento de trabalhadores com exposição ocupacional a agrotóxicos bem ações e intervenções educacionais, em busca da integralidade da atenção à sua saúde, de familiares e comunidade, com vistas à prevenção de agravos e redução dos índices crescentes de câncer nesta população.

\section{Referências}

Abreu, P. H. B., \& Alonzo, H. G. A. (2016). O agricultor familiar e o uso (in)seguro de agrotóxicos no município de Lavras/MG. Rev Bras Saúde Ocup, 41, e18. https://doi.org/10.1590/2317-6369000130015. 
Barroso, L. B., \& Wolff, D. B. (2009). Riscos e segurança do aplicador de agrotóxicos no Rio Grande do Sul. Rev Disc. Scientia, 10(1), $27-52$. https://periodicos.ufn.edu.br/index.php/disciplinarumNT/article/view/1253

Bassig, B. A., Engel, L. S., Langseth, H., Grimsrud, T. K., Cantor, K. P., Vermeulen, R., Purdue, M. P., Barr, D. B., Wong, J. Y. Y., Blair, A., Rothman, N., \& Lan, Q. (2019). Pre-diagnostic serum concentrations of organochlorines and risk of acute myeloid leukemia: a nested case-control study in the Norwegian Janus Serum Bank Cohort. Environment International, 125, 229-235. https://www.sciencedirect.com/science/article/pii/S0160412018317562?via\%3Dihub.

Battisti, V., Bagatini, M. D., Maders, L. D., Chiesa, J., Santos, K. F., Gonçalves, J. F., Abdalla, F. H., Battisti, I. E., Schetinger, M. R., \& Morsch, V. M. (2012). Cholinesterase activities and biochemical determinations in patients with prostate cancer: influence of Gleason score, treatment and bone metastasis. Biomedicine \& Pharmacotherapy, 66(4), 249-255. https://www.sciencedirect.com/science/article/pii/S0753332211001545

Boulanger, M., Tual, S., Lemarchand, C., Guizard, A. V., Velten, M., Marcotullio, E., Baldi, I., Clin, B., \& Lebailly, P. (2017). Agricultural exposure and risk of bladder cancer in the AGRIculture and CANcer cohort. International Archives Occupational and Environmental Health, 90(2), 169-178. https://www.researchgate.net/publication/309734693_Agricultural_exposure_and_risk_of_bladder_cancer_in_the_AGRIculture_and_CANcer_cohort

Brasil. (2002). Decreto $n^{\circ} 4.074$, de 4 de janeiro de 2002. Regulamenta a Lei n ${ }^{\circ} 7.802$, de 11 de julho de 1989, que dispõe sobre a pesquisa, a experimentação, a produção, a embalagem e rotulagem, o transporte, o armazenamento, a comercialização, a propaganda comercial, a utilização, a importação, a exportação, o destino final dos resíduos e embalagens, o registro, a classificação, o controle, a inspeção e a fiscalização de agrotóxicos, seus componentes e afins, e dá outras providências. Brasília: Casa Civil. http://www.planalto.gov.br/ccivil_03/decreto/2002/d4074.htm.

Carneiro, F. F., Augusto, L. G. S., Rigotto, R. M., Friedrich, K., \& Búrigo, A.C. (2015). Dossiê ABRASCO: um alerta sobre os impactos dos agrotóxicos na saúde. Rio de Janeiro: EPSJV, São Paulo: Expressão Popular. https://www.arca.fiocruz.br/handle/icict/26221

Dasgupta, S., Meisner, C., \& Huq, M. (2005). Health effects and pesticide perception as determinants of pesticide use: evidence from Bangladesh. Policy Research Working Paper, 3776, 1-19.

Depczynski, J., Dobbins, T., Armstrong, B., \& Lower, T. (2018). Comparison of cancer incidence in Australian farm residents 45 years and over, compared to rural non-farm and urban residents - a data linkage study. BMC Cancer, 18(33), 1-12. https://www.ncbi.nlm.nih.gov/pmc/articles/PMC5756349/.

Estrela, C. (2018). Metodologia Científica: Ciência, Ensino, Pesquisa. Editora Artes Médicas.

Faria, N. M. X., Facchini, L. A., Fassa, A. G., \& Tomasi, E. (2004). Trabalho rural e intoxicações por agrotóxicos. Cadernos de Saúde Pública, 20(5), 12981308. http://dx.doi.org/10.1590/S0102-311X2004000500024.

Faria, N. M. X., Fassa, A. G. \& Meucci, R. D. (2014). Association between pesticide exposure and suicide rates in Brazil. NeuroToxicology, 45, 355-362. https://www.sciencedirect.com/science/article/pii/S0161813X14000849?via\%3Dihub.

Fundação Nacional de Saúde. (1998). Guia de vigilância epidemiológica.

Hermes Pardini. Help de exames, Colinesterase eritrocitária. http://www.labhpardini.com.br/scripts/mgwms32.dll?MGWLPN=HPHOST BS\&App=HELPE\&EXAME $=$ S\% 7C $\% 7 C C O L I N$

Instituto Brasileiro de Geografia e Estatística - IBGE. Censo agropecuário 2006 - Brasil, Grandes Regiões e Unidades da Federação. https://biblioteca.ibge.gov.br/index.php/biblioteca-catalogo?id=750\&view=detalhes

Instituto Brasileiro de Geografia e Estatística. (2010). Um panorama da saúde no Brasil: acesso e utilização de serviços, con dições de saúde e fatores de risco e proteção à saúde - 2008.

International Agency for Research on Cancer. (2017). Monographs on the Evaluation of Carcinogenic Risks to Humans - Volume 112: Some organophosphate insecticides and herbicides.

Jobim, P. F. C., Nunes, L. N., Giugliani, R., \& Cruz, I. B. M. (2010). Existe uma associação entre mortalidade por câncer e uso de agrotóxicos? Uma contribuição ao debate. Ciência \& Saúde Coletiva, 15(1), 277-288. https://dx.doi.org/10.1590/S1413-81232010000100033

Kongtip, P., Changfuang, S., Yoosook, W., Chantanakul, S., \& Sujirarat, D. (2011). Ethion exposure and biological monitoring in vegetable farmers. Journal of the Medical Association of Thailand, 94(3), 286-294. https://pubmed.ncbi.nlm.nih.gov/21560835/

Kongtip, P., Nankongnab, N., Mahaboonpeeti, R., Bootsikeaw, S., Batsungnoen, K., Hanchenlaksh, C., Tipayamongkholgul, M., \& Woskie, S. (2018). Differences among Thai agricultural workers' health, working conditions, and pesticide use by farm type. Annals of Work Exposures and Health, 62(2), 167181. https://academic.oup.com/annweh/article/62/2/167/4830215.

Lemarchand, C., Tual, S., Levêque-Morlais, N., Perrier, S., Belot, A., Velten, M., Guizard, A. V., Marcotullio, E., Monnereau, A., Clin, B., Baldi, I., \& Lebailly, P. (2017). Cancer incidence in the AGRICAN cohort study (2005-2011). Cancer Epidemiology, 49, 175-185. https://www.ncbi.nlm.nih.gov/pmc/articles/PMC6200131/.

Machado, L. M., Beck, C. L. C., Coelho, A. P. F., Weiller, T. H., \& Camponogara, S. (2017). Atuação dos profissionais de saúde da família frente ao trabalhador rural exposto a agrotóxicos. Ciência, Cuidado e Saúde, 16(3), 1-8. http://periodicos.uem.br/ojs/index.php/CiencCuidSaude/article/view/37051.

Manyilizu, W. B., Mdegela, R. H., Helleve, A., Skjerve, E., Kazwala, R., Nonga, H., Muller, M., Lie, E., \& Lyche, J. (2017). Self-Reported Symptoms and Pesticide Use among Farm Workers in Arusha, Northern Tanzania: A Cross Sectional Study. Toxics, 5(4), 24. https://doi.org/10.3390/toxics5040024

Mello, C. M., \& Silva, L. F. (2013). Fatores associados à intoxicação por agrotóxicos: estudo transversal com trabalhadores da cafeicultura no sul de Minas Gerais. Epidemiologia e Serviços de Saúde, 22(4), 609-620. http://scielo.iec.gov.br/pdf/ess/v22n4/v22n4a07.pdf.

Ministério do Trabalho e Emprego. (1978). NR 7 - Programa de controle médico de saúde ocupacional. http://www.guiatrabalhista.com.b $\mathrm{r} /$ legislacao/nr/nr7.htm. 
Ministério do Trabalho e Emprego. (2005). NR 31 - Segurança e saúde no trabalho na agricultura, pecuária silvicultura, exploração florestal e aquicultura. ttp://www.guiatrabalhista.com.br/legislacao/nr/nr31.htm.

Morin, P. V., \& Stumm, E. M. F. (2018). Transtornos mentais comuns em agricultores, relação com agrotóxicos, sintomas físicos e doenças preexistentes. Psico, 49(2), 196-205. http://revistaseletronicas.pucrs.br/jgergeron/ojs/index.php/revistapsico/article/view/26814.

Moura, L. T. R., Morais, R. J. L., Dias, A. C. S., \& Bedor, C. N. G. (2014). Perfil epidemiológico dos casos de intoxicação por agrotóxicos. Revista de Enfermagem UFPE, 8(7), 2333-2341. https://periodicos.ufpe.br/revistas/revistaenfermagem/article/view/9923

Naidoo, S., London, L., Rother, H. A., Burdorf, A., Naidoo, R. N., \& Kromhout, H. (2010). Pesticide safety training and practices in women working in smallscale agriculture in South Africa. Occupational and environmental medicine, 67(12), 823-828. https://doi.org/10.1136/oem.2010.055863

Neves, P. D. M. \& Bellini, M. (2013). Intoxicações por agrotóxicos na mesorregião norte central paranaense, Brasil - 2002 a 2011. Ciência \& Saúde Coletiva, 18(11), 3147-3158. https://doi.org/10.1590/S1413-81232013001100005

Pasiani, J. O., Torres, P., Silva, J. R., Diniz, B. Z., \& Caldas, E. D. (2012). Knowledge, attitudes, practices and biomonitoring of farmers and residents exposed to pesticides in Brazil. International Journal of Environmental Research and Public Health, 9(9), 3051-3068. https://www.ncbi.nlm.nih.gov/pmc/articles/PMC3499853/

Pena, R. F. A. (2019). População Economicamente Ativa - PEA. Brasil Escola. https://brasilescola.uol.com.br/geografia/populacao-economicamente-ativapea.htm.

Piel, C., Pouchieu, C., Tual, S., Migault, L., Lemarchand, C., Carles, C., Boulanger, M., Gruber, A., Rondeau, V., Marcotullio, E., Lebailly, P., Baldi, I., \& AGRICAN group (2017). Central nervous system tumors and agricultural exposures in the prospective cohort AGRICAN. International journal of cancer, $141(9), 1771-1782$. https://doi.org/10.1002/ijc.30879

Ramírez-Santana, M., Farías-Gómez, C., Zúñiga-Venegas, L., Sandoval, R., Roeleveld, N., Van der Velden, K., Scheepers, P., \& Pancetti, F. (2018). Biomonitoring of blood cholinesterases and acylpeptide hydrolase activities in rural inhabitants exposed to pesticides in the Coquimbo Region of Chile. PloS one, 13(5), e0196084. https://doi.org/10.1371/journal.pone.0196084

Ramos, H. (2006). EPIs, trabalhador exemplar é trabalhador seguro. https://edcentaurus.com.br/agranja/edicao/695/materia/588.

Rigotto, R. M., Silva, A. M. C., Ferreira, M. J. M., Rosa, I. F. \& Aguiar, A. C. P. (2013). Tendências de agravos crônicos à saúde associados a agrotóxicos em região de fruticultura no Ceará, Brasil. Revista Brasileira de Epidemiologia, 16(3), 763-773. https://www.scielo.br/scielo.php?pid=S1415790X2013000300763\&script=sci_arttext\&tlng=pt

Rigotto, R. M., Vasconcelos, D. P. \& Rocha, M. M. (2014). Uso de agrotóxicos no Brasil e problemas para a saúde pública. Cadernos de Saúde Pública, 30(7), 1-3. http://dx.doi.org/10.1590/0102-311XPE020714

Santana, C. M., Costa, A. R., Nunes, R. M. P., Nunes, N. M. F., Peron, A. P., Melo-Cavalcante, A. A. C., \& Ferreira, P. M. P. (2016). Exposição ocupacional de trabalhadores rurais a agrotóxicos. Cadernos Saúde Coletiva, 24(3), 301-307. https://doi.org/10.1590/1414-462x201600030199

Silva, J. M., Novato-Silva, E., Faria, H. P., \& Pinheiro, T. M. M. (2005). Agrotóxico e trabalho: uma combinação perigosa para a saúde do trabalhador rural. Ciência \& Saúde Coletiva, 10(4), 891-903, 2005. https://doi.org/10.1590/S1413-81232005000400013

Silva, F. M., Sobrinho, L. G. A., Coelho, D. C., Ferreira, P. M. L., \& Azevedo, P. B. (2014). Percepção de risco no uso de ag rotóxicos em cinco comunidades rurais no município de Pombal - PB. Revista Verde de Agroecologia e Desenvolvimento Sustentável, 9(5), 1-9. https://www.gvaa.com.br/revista/index.php/RVADS/article/view/3179.

Silvério, A., Machado, S. C., Azevedo, L., Nogueira, D. A., de Castro Graciano, M. M., Simões, J. S., Viana, A., \& Martins, I. (2017). Assessment of exposure to pesticides in rural workers in southern of Minas Gerais, Brazil. Environmental toxicology and pharmacology,55, 99-106. https://doi.org/10.1016/j.etap.2017.08.013

Sistema Nacional de Informações Tóxico-Farmacológicas. (2015). Dados de intoxicação, Dados nacionais. https://sinitox.icict.fiocruz.br/dados-nacionais.

Soares, W. L., Freitas, E. A. V., \& Coutinho, J. A. G. (2005). Trabalho rural e saúde: intoxicações por agrotóxicos no município de Teresópolis - RJ. Revista de Economia e Sociologia Rural, 43(4), 685-701. https://doi.org/10.1590/S0103-20032005000400004

Sorensen, J. A., Tinc, P. J., Weil, R., \& Droullard, D. (2017). Symbolic Interactionism: A Framework for Understanding Risk-Taking Behaviors in Farm Communities. Journal of agromedicine, 22(1), 26-35. https://doi.org/10.1080/1059924X.2016.1248306

Souza Filho, H. M., Buainain, A. M. \& Guanziroli, C. (2004). Agricultura familiar e tecnologia no Brasil: características, desafios e obstáculos. In: congresso da sociedade brasileira de economia, administração e social rural, 42, 2004, Cuiabá. Anais... SOBER. 